University of South Florida

DIGITAL COMMONS

Digital Commons @ University of

@ UNIVERSITY OF SOUTH FLORIDA

South Florida

$1-2011$

\title{
An Empirical Approach to Derive MODIS Ocean Color Patterns under Severe Sun Glint
}

Chuanmin $\mathrm{Hu}$

University of South Florida, huc@usf.edu

Follow this and additional works at: https://digitalcommons.usf.edu/msc_facpub

Part of the Life Sciences Commons

\section{Scholar Commons Citation}

Hu, Chuanmin, "An Empirical Approach to Derive MODIS Ocean Color Patterns under Severe Sun Glint" (2011). Marine Science Faculty Publications. 1875.

https://digitalcommons.usf.edu/msc_facpub/1875

This Article is brought to you for free and open access by the College of Marine Science at Digital Commons @ University of South Florida. It has been accepted for inclusion in Marine Science Faculty Publications by an authorized administrator of Digital Commons @ University of South Florida. For more information, please contact digitalcommons@usf.edu. 


\title{
An empirical approach to derive MODIS ocean color patterns under severe sun glint
}

\author{
Chuanmin $\mathrm{Hu}^{1}$ \\ Received 7 September 2010; revised 8 October 2010; accepted 18 October 2010; published 11 January 2011.
}

[1] Oil tracking in the Gulf of Mexico in response to the Deepwater Horizon accident requires timely and accurate observations of major circulation patterns such as the Loop Current and LC eddies. When the eastern GOM becomes nearly isothermal at the surface and the use of sea surface temperature imagery is limited, MODIS ocean color data can be used instead. However, frequent and extensive sun glint prevents such an application when glint reflectance, $L_{\mathrm{g}}$, is $>0.01 \mathrm{sr}^{-1}$. Here, an empirical approach is developed to remove sun glint and clouds based on band ratios between the Rayleigh-corrected reflectance $\left(R_{\mathrm{rc}}\right)$ at $469,555,645,859$, and 1240-nm. To minimize the effect of residual errors due to variable aerosols and imperfect glint correction, a color index (CI) is derived to represent the color patterns. Comparison between results from adjacent days with different glint and aerosol patterns suggests that the approach is able to derive consistent color patterns under severe sun glint $\left(L_{\mathrm{g}}<0.15 \mathrm{sr}^{-1}\right)$. Tests of the approach over the Tropical Atlantic, East China Sea, and ocean waters off South Africa further validate the approach's general applicability. The color index (CI) also shows significant correlation with MODIS band-ratio $\mathrm{Chl}\left(<1 \mathrm{mg} \mathrm{m}^{-3}\right)$ for each case examined. The simple design of the approach makes it straightforward to implement for other subtropical and tropical regions when a qualitative MODIS CI is desired to infer circulation patterns and to trace eddies under severe sun glint. Citation: Hu, C. (2011), An empirical approach to derive MODIS ocean color patterns under severe sun glint, Geophys. Res. Lett., 38, L01603, doi:10.1029/2010GL045422.

\section{Introduction}

[2] Tremendous success has been achieved in establishing a long-term data record for several key parameters derived from satellite ocean color measurements [McClain et al., 2004, and references therein]. The data products, starting from the CZCS (1978-1986) era to today's SeaWiFS, MODIS, MERIS, and other sensors, have seen continuously increasing usage in various Earth Science disciplines, from research, management, to education (see technical report series of the International Ocean Color Coordination Group).

[3] Nearly all previous efforts in ocean color algorithm development have focused on accurate, validated bio-optical data products such as surface chlorophyll-a concentrations (Chl) [O'Reilly et al., 2000, and references therein]. Accuracy is the key because time-series analyses call for the most

\footnotetext{
${ }^{1}$ College of Marine Science, University of South Florida, St. Petersburg, Florida, USA.

Copyright 2011 by the American Geophysical Union. 0094-8276/11/2010GL045422
}

robust products to study temporal changes. However, there are cases where accuracy should be relaxed to allow for more data coverage. An example is when ocean color patterns are more important than absolute Chl values. In these cases, the current accuracy-driven algorithm/processing design often makes observation difficult under non-optimal conditions, for example when significant sun glint is present (Figure 1a).

[4] The recent Gulf of Mexico (GOM) oil spill event represents an example of such a case. Following a massive explosion and fire burning on 20-21 April 2010, the resultant Deepwater Horizon oil spill posed an unprecedented threat to the GOM ecosystems. Numerous efforts from Federal and state agencies, academia, environmental groups, and private entities were made to monitor, study, and mitigate the potential impacts. One such effort was oil tracking by combining satellite observations and numerical modeling (Y. Liu et al., Tracking the Deepwater Horizon oil spill: A modeling perspective, submitted to Eos, Transactions, American Geophysical Union, 2010).

[5] The oil tracking effort has two components. The first is to delineate surface oil slicks using MODIS imagery [ $\mathrm{Hu}$ et al., 2009] and Synthetic Aperture Radar imagery [Liu et al., 2000]. The second is to model and observed circulation patterns such as the Loop Current and LC eddies that may pull the oil to reach remote regions such as the Atlantic Ocean [e.g., Hu et al., 2005]. During the summer months, the GOM becomes isothermal at the surface with minimal spatial contrast in sea surface temperature. During this period, ocean color imagery could be used to observe spatial patterns to infer circulations (data from altimeters have much lower resolution and are not available in near real-time). Unfortunately, when the default NASA processing software (SeaDAS6.1) is used to process the data, an image mask is created for the areas under significant and extensive sun glint, making the image useless (Figure 1b). This is due to both unreliable glint correction and saturation of the $1-\mathrm{km}$ ocean color bands.

[6] Recognizing the pressing need to observe ocean circulation patterns in near real-time in response to the unprecedented oil spill, the objective of this work is to develop a new approach to derive MODIS ocean color patterns under severe sun glint. The manuscript is arranged as follows. The background for glint correction is briefly introduced, followed by the approach to derive a color index (CI) using a baseline subtraction method, and the approach for glint correction and cloud masking. Finally, the accuracy and potential application of the MODIS CI imagery for the global ocean are discussed.

\section{Current Glint Correction}

[7] The satellite measured radiance from an image pixel, after correction for gaseous absorption, comes from several sources:

$$
\begin{aligned}
L_{\mathrm{t}, \lambda}(\Theta)= & L_{\mathrm{r}, \lambda}(\Theta)+L_{\mathrm{a}, \lambda}(\Theta)+T_{\lambda}(\theta) T_{0, \lambda}\left(\theta_{0}\right) F_{0, \lambda} L_{g}(\Theta) \\
& +t_{\lambda}(\theta) L_{\mathrm{w}, \lambda}(\Theta),
\end{aligned}
$$



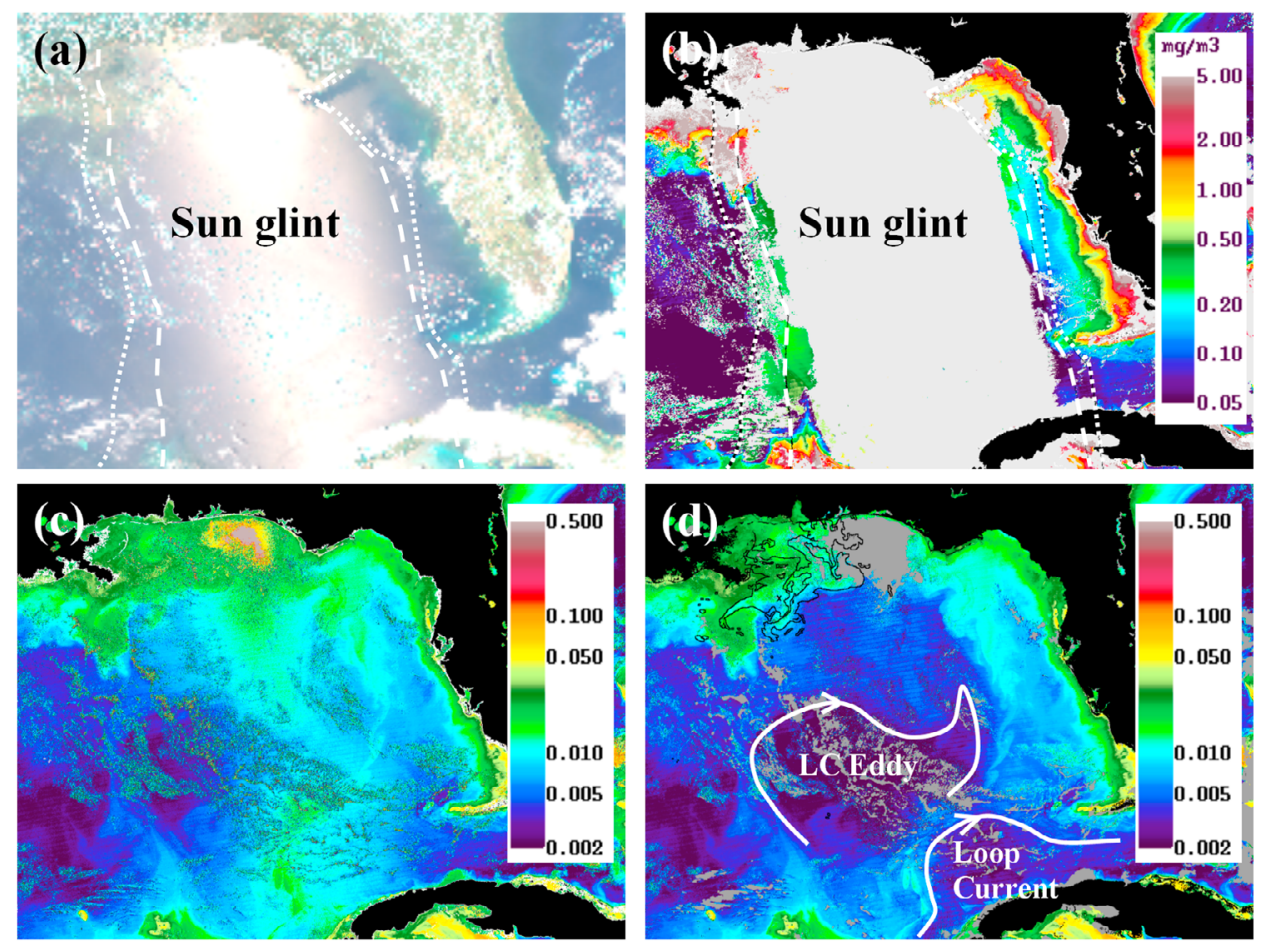

Figure 1. An example of sun glint induced problems in the current MODIS data products, and the corrected products on 12 June 2010 (18:50 GMT). (a) RGB image composed from three land bands (R: $645 \mathrm{~nm}, \mathrm{G}: 555 \mathrm{~nm}, \mathrm{~B}: 469 \mathrm{~nm}$ ) shows significant sun glint in the eastern GOM $\left(22-31^{\circ} \mathrm{N}, 91-79^{\circ} \mathrm{W}\right)$. The dotted and dashed lines denote sun glint reflectance, $L_{\mathrm{g}}=0.005$ and $0.01 \mathrm{sr}^{-1}$, respectively. (b) MODIS Chl estimated using SeaDAS6.1, after several pre-defined masks were removed and several flagging threshold values were increased. Note that $L_{\mathrm{g}}>0.005 \mathrm{sr}^{-1}$ is regarded as significant in SeaDAS6.1 [Wang and Bailey, 2001]. (c) MODIS color index (CI) image derived from the three land bands. The CI values over clouds and in the glint region are elevated. (d) The same CI image after correcting the glint contamination and masking clouds (grey color). Surface oil locations are outlined in black. The major circulation patterns such as the Loop Current and LC Eddies are clearly visible. To plot the CI values in log scale, an arbitrary offset of 0.011 is added.

where $\lambda$ is the wavelength, $L_{\mathrm{r}}$ is from Rayleigh scattering, $L_{\mathrm{a}}$ is from scattering by aerosols and aerosol-Rayleigh interactions, $t$ is the pixel-to-satellite diffuse transmittance, $L_{\mathrm{w}}$ is the water-leaving radiance, $T$ and $T_{0}$ are the pixel-to-satellite (view angle: $\theta$ ) and sun-to-pixel (solar zenith: $\theta_{0}$ ) beam transmittance, respectively, $F_{0}$ is the extraterrestrial solar irradiance, and $L_{\mathrm{g}}$ is the normalized sun glint reflectance (in units of $\mathrm{sr}^{-1}$ ) that depends only on the sea state and solar-viewing geometry $(\Theta)$. For simplicity, whitecap contribution is omitted here.

[8] The ultimate goal of the atmospheric correction (including glint correction) is to derive $L_{\mathrm{w}}$ from $L_{\mathrm{t}}$. The procedure of using near-infrared bands to derive aerosol properties and then correct the visible bands in the absence of sun glint has been described by Gordon and Wang [1994].

[9] When sun glint is present, Wang and Bailey [2001] developed a procedure (based on Cox and Munk's [1954] model to estimate sea surface roughness) to model $L_{\mathrm{g}}$ using surface winds and $\Theta$, and the correction was implemented in SeaDAS. The correction is supposed to derive reliable $L_{\mathrm{w}}$ for $L_{\mathrm{g}}<0.01 \mathrm{sr}^{-1}$, beyond which an image mask is created to prevent further processing (the pixels with $0.005<L_{\mathrm{g}}<$ $0.01 \mathrm{sr}^{-1}$ are flagged as "high glint"). However, Figure 1 shows an example where most of the eastern GOM has $L_{\mathrm{g}}>0.01 \mathrm{sr}^{-1}$. Even after the SeaDAS processing options are forced to bypass the flag checking, most of the pixels are still masked (Figure 1b) due to atmospheric correction failure (the correction was not designed to deal with high reflectance in the near-IR or shortware-IR). Aside from the glint contamination, MODIS 1-km ocean color bands saturate over bright targets. The saturation radiance for bands $547,667,748$, and $869 \mathrm{~nm}$ is about $6.96,3.50,2.23$, and $1.30 \mathrm{~mW} \mathrm{~cm} \mathrm{~cm}^{-1} \mathrm{sr}^{-1}$, respectively. For $\theta_{\mathrm{o}}=30^{\circ}$, these values correspond to at-sensor reflectance of $10.1 \%, 6.3 \%$, $4.75 \%$, and $3.7 \%$, respectively.

[10] Another correction approach is to derive the glint contribution from the measured near-IR radiance [Hochberg et al., 2003] instead of a wind-dependent model. The relative glint patterns are first derived from the NIR band (scaled by the darkest and brightest pixels), and then used to subtract the glint contribution proportionally from the coregistered visible bands. One limitation of this approach is the lack of the correction term $T_{\lambda}(\theta) T_{0, \lambda}\left(\theta_{0}\right)$ (equation (1)), which depends not only on the pixel location but also on wavelength. For a small Ikonos image the term may be assumed as a constant, but this assumption is no longer valid for large-swath (2330-km) MODIS images.

\section{An Ocean Color Index}

[11] Since MODIS ocean bands at 1-km resolution saturate over severe sun glint, MODIS land bands at $500-\mathrm{m}$ and $250-\mathrm{m}$ resolutions must be used. These bands were 

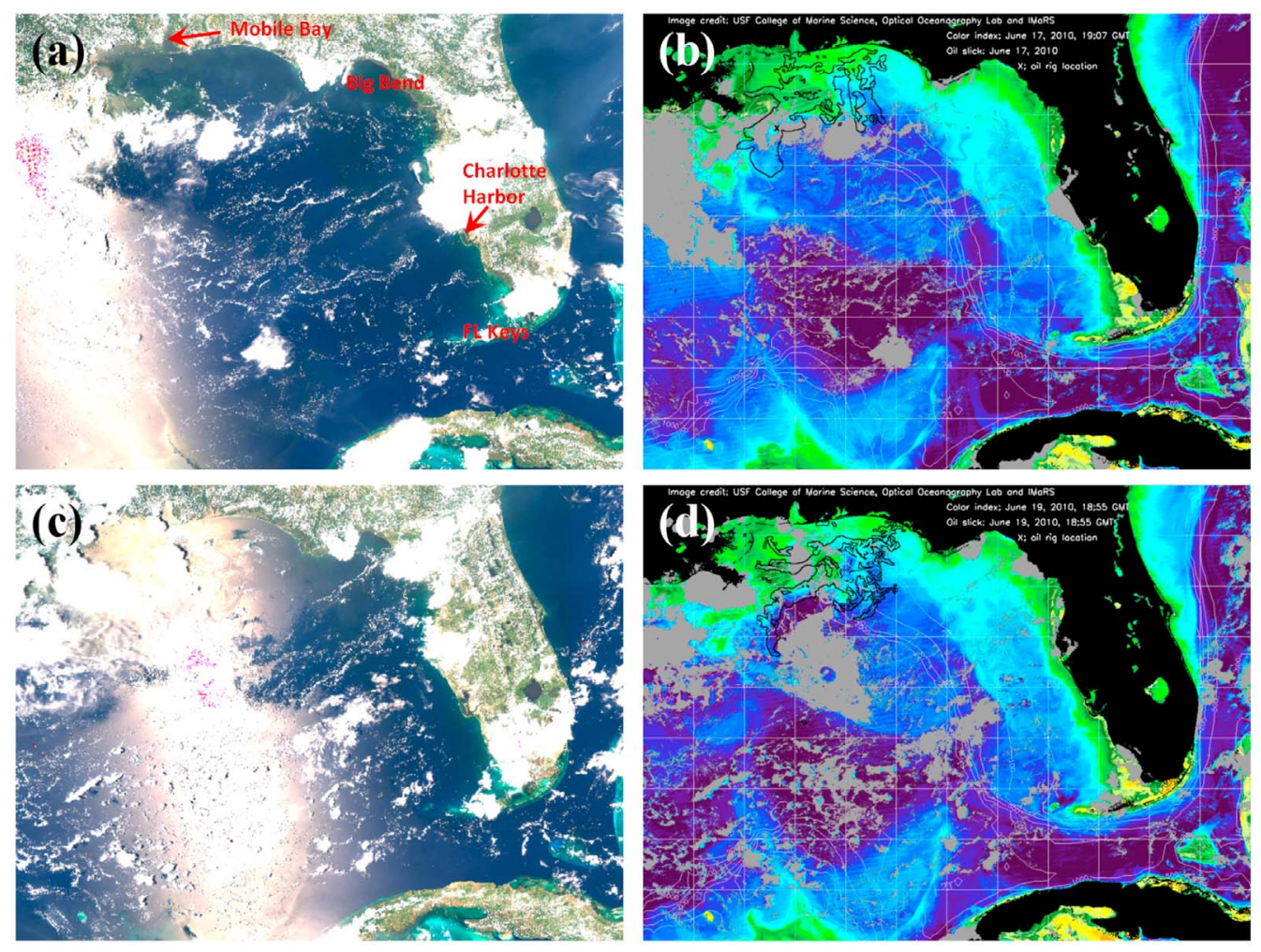

Figure 2. MODIS RGB and CI images for ( $a$ and b) 17 June 2010 (19:07 GMT) and (c and d) 19 June 2010 (18:55 GMT), respectively. Although the glint patterns are different, the derived CI patterns are consistent. Overlaid on the CI images are the surface oil locations (black outlines) determined from MODIS and SAR observations. Color legends are shown in Figures $1 \mathrm{c}$ and $1 \mathrm{~d}$.

designed to cover a higher dynamic range at the price of lower signal-to-noise ratio for the ocean, but are sufficient to observe color patterns. Here, a color index (CI) is derived as:

$$
\begin{gathered}
\mathrm{CI}=R_{\mathrm{rc}, 555}-R_{\mathrm{rc}, 555^{\prime},} \\
R_{\mathrm{rc}, 555^{\prime}}=R_{\mathrm{rc}, 469}+\left(R_{\mathrm{rc}, 645}-R_{\mathrm{rc}, 469}\right) \times\left(\lambda_{555}-\lambda_{469}\right) /\left(\lambda_{645}-\lambda_{469}\right), \\
R_{\mathrm{rc}, \lambda}=\pi L_{\mathrm{t}, \lambda} /\left[F_{\mathrm{o}} \cos \left(\theta_{\mathrm{o}}\right)\right]-\pi L_{\mathrm{r}, \lambda} /\left[F_{\mathrm{o}} \cos \left(\theta_{\mathrm{o}}\right)\right],
\end{gathered}
$$

where $R_{\mathrm{rc}}$ is the Rayleigh-corrected reflectance and the numbers denote MODIS wavelengths in nanometers. $\mathrm{CI}$ is actually $R_{\mathrm{rc}, 555}$ normalized against a linear baseline between 469 and $645 \mathrm{~nm}$.

[12] Figure 1c shows the MODIS CI image. There is no longer data saturation or image mask. However, two problems exist. The first is that the color patterns are distorted (high CI values) under sun glint. This is because of the relatively lower $T_{469} T_{0,469}$ and lower $R_{\mathrm{rc}, 555}$ in equation (2). The second is that cloud pixels show high CI values. These artifacts need to be corrected.

\section{Empirical Glint Correction}

[13] Glint contribution to $R_{\mathrm{rc}}$ is proportional to $T(\theta) T_{0}\left(\theta_{0}\right)$ $L_{\mathrm{g}}(\Theta)$ (equation (1)), where both $T$ and $T_{0}$ depend on $L_{\mathrm{r}}$ (known) and $L_{\mathrm{a}}$ (unknown). Although $L_{\mathrm{g}}$ can be modeled [Wang and Bailey, 2001], the accuracy depends on wind (110-km per pixel resolution) and bottom depth. The model artifacts, independent of the MODIS measurements, can induce large errors for 1-km or higher resolution MODIS data when $L_{\mathrm{g}}$ is $>0.01 \mathrm{sr}^{-1}$.

[14] Based on these considerations, an empirical, partial correction was developed. Visual examination of several images in June 2010 in the eastern GOM suggested that $R_{\mathrm{rc}, 859}=0.02$ might be used as a threshold to find pixels with glint contamination, and glint contribution in other bands was scaled to $R_{\mathrm{rc}, 859}$ as:

$\mathrm{R}_{\mathrm{g}, 469}=\alpha\left(\mathrm{R}_{\mathrm{rc}, 859}-0.02\right), \mathbf{R}_{\mathrm{g}, 555}=\beta\left(\mathrm{R}_{\mathrm{rc}, 859}-0.02\right)$,

$R_{g, 645}=\gamma\left(R_{r c, 859}-0.02\right)$.

$R_{\mathrm{g}}$ was then subtracted from $R_{\mathrm{rc}}$, with the latter used in equation (2) to derive the CI. The coefficients were determined through analyzing the statistical relationships between the visible and NIR bands in glint and glint-free $\left(L_{\mathrm{g}}<0.001 \mathrm{sr}^{-1}\right)$ regions from the June 2010 images, and through trial-and-error adjustment until consistent color patterns can be observed between adjacent glint and glintfree regions. The coefficients were determined as $\alpha=0.73$, $\beta=0.87$, and $\gamma=0.93$, and they were used to process all glint-contaminated images since June 2010. Figure 1d shows the corrected CI image corresponding to Figure 1c.

\section{Empirical Cloud Masking}

[15] A simple threshold method of cloud masking will not work because both clouds and sun glint are bright (high $R_{\mathrm{rc}}$ 


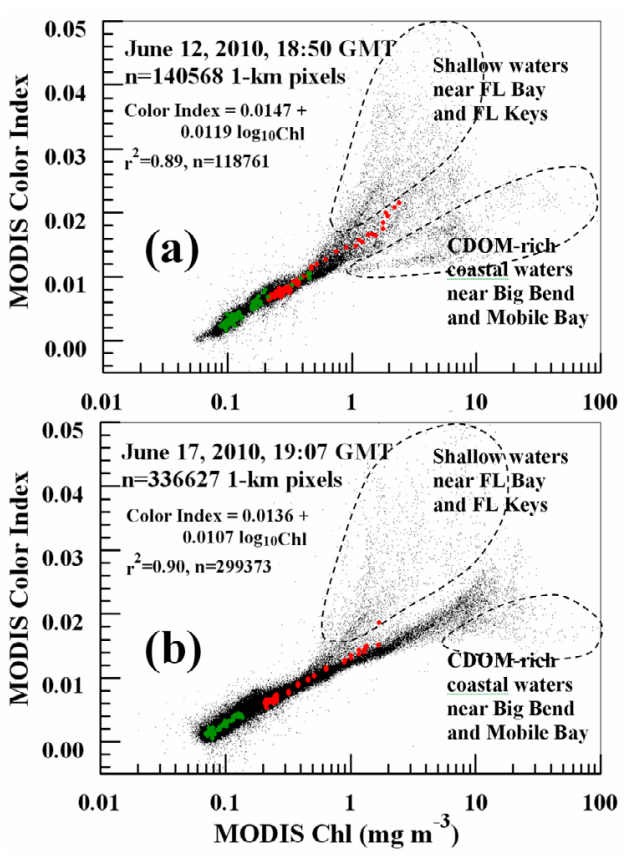

Figure 3. Comparison between MODIS CI and MODIS band-ratio Chl on (a) 12 and (b) 17 June 2010. Significant correlation is found for $\mathrm{Chl}<1 \mathrm{mg} \mathrm{m}^{-3}$, which represents $>85 \%$ of the MODIS pixels. The data scatter for higher $\mathrm{Chl}$ is due to the different modulations to the MODIS $R_{\mathrm{rc}}$ spectra by CDOM, suspended sediments, and shallow bottom. The red and green symbols denote data from two arbitrary nearshore-offshore transects near Charlotte Harbor and Florida Keys (Figure $2 b)$, respectively.

values). More sophisticated methods [e.g., Frey et al., 2008] use $1-\mathrm{km}$ thermal bands and other tests to flag clouds. The $1-\mathrm{km}$ resolution may not be adequate for the $500-\mathrm{m}$ data, and its ability to differentiate sun glint from clouds is yet to be tested.

[16] Based on the fact that sun glint is more reddish than clouds, an empirical method was developed through examining the statistical relationship between the spectral bands for glint and cloud pixels, respectively, from the June 2010 images. A pixel is classified as cloud if

$$
\begin{gathered}
\mathrm{R}_{\mathrm{rc}, 1240} \geq 0.35 \text {, or } \\
0.04<\mathrm{R}_{\mathrm{rc}, 1240}<0.35 \text { and } \mathrm{S}\left(R_{\mathrm{rc}, 469}, R_{\mathrm{rc}, 555}\right)<-0.06,
\end{gathered}
$$

where the shape factor is defined as: $\mathrm{S}\left(R_{\mathrm{rc}, 469}, R_{\mathrm{rc}, 555}\right)=$ $R_{\mathrm{rc}, 555}-1.27^{*} R_{\mathrm{rc}, 469}$. This method basically lifts the cloud threshold of $R_{\mathrm{rc}, 1240}=0.0235$ [Wang and Shi, 2006] to 0.04, because the baseline subtraction method can effectively remove thin-cloud contaminations [e.g., $\mathrm{Hu}, 2009$ ].

\section{Examples}

[17] Figure 1d shows that the empirical glint correction led to consistent color patterns between glint and glintfree regions, and the empirical cloud masking was able to distinguish clouds from glint for $L_{\mathrm{g}}<0.15 \mathrm{sr}^{-1}$. This is 15 times higher than the glint mask threshold used in SeaDAS. Further, the downgrade in resolution from $500-\mathrm{m}$ to 1-km removed small (1-2 500-m pixels) clouds to improve visualization. Other examples from adjacent days in Figure 2 show similar results, where CI patterns in the same regions appear consistent through time, even when glint patterns varied significantly. The circulation patterns of the LC and LC eddies are clearly visible in these de-glinted images. More examples for other regions (Tropical Atlantic, East China Sea, and waters off South Africa) are provided in the auxiliary material. ${ }^{1}$

\section{Discussion: Accuracy and Application}

[18] The CI method differs from the traditional band-ratio algorithms because of its use of the linear baseline subtraction. Previous efforts using baseline subtraction focused on the red and NIR bands to detect algal blooms [Letelier and Abott, 1996; Gower et al., 2005; Hu, 2009], and this is the first time that a blue-green-red band subtraction is attempted. $H u$ [2009] showed that when detecting floating algae, a baseline subtraction is impacted less by atmospheric correction errors or changes in aerosols/observing conditions than is a band-ratio method. This is primarily because those errors are linearly proportional to wavelength to the first order, and therefore can be subtracted. Likewise, the residual errors of the empirical glint correction as well as errors induced by the threshold of $R_{\mathrm{rc}, 859}=0.02$ may be removed, at least in part, by the linear subtraction in the CI method.

[19] Thus, the baseline subtraction method works because 1) most of the aerosol effects and glint effects are removed by subtraction, and 2) in most open oceans the $469-\mathrm{nm}$ band is more sensitive than the 555- and 645-nm bands to changes in biomass (Chl), and $\mathrm{CI}$ is effectively a measure of the relative changes between 469 and $555 \mathrm{~nm}$. If Chl can be derived using the 469/555 ratio, in principle it can also be derived using the 469-555-645 CI. Indeed, even though the objective here is to derive the relative color patterns, Figure 3 shows that $\mathrm{CI}$ is significantly correlated with $\mathrm{Chl}$ for $\mathrm{Chl}<1 \mathrm{mg}$ $\mathrm{m}^{-3}$, and the relationship appears to be stable over time. If we were to derive $\mathrm{Chl}$ on 17 June using CI on 17 June and the relationship from 12 June, the RMS "error" in the CI-derived Chl would be $20.5 \%$ (0.085 in log scale) for all data points with $\mathrm{CI} \leq 0.02(\mathrm{n}=298907)$ (this represents all "clear-water" pixels in the eastern GOM). Further, most of the scatter for $\mathrm{Chl}<1 \mathrm{mg} \mathrm{m}^{-3}$ originates from different geographic regions (e.g., LC eddies, NE GOM, central-west Florida), which will not affect the color contrast in the CI image for a given region. For example, much tighter relationships are observed between $\mathrm{CI}$ and $\mathrm{Chl}$ in two arbitrary nearshore-offshore transects near Charlotte Harbor and Florida Keys (red and green symbols in Figure 3, respectively). Therefore, for most waters (in the 12 and 17 June cases, $>85 \%$ of the valid pixels), CI may be used as a relatively stable index for Chl.

[20] The limited examples above show preliminary success of the approach for the GOM since June 2010. Can it be extended to other regions? Although a complete evaluation over the entire global data archive is difficult to achieve due to the data volume, several regions were randomly selected, including the Tropical Atlantic (Amazon River plume and North Brazil Current), the East China Sea (Yangtze River

\footnotetext{
${ }^{1}$ Auxiliary materials are available in the HTML. doi:10.1029/ 2010 GL045422.
} 
plume), and waters off South Africa. These cases represent a variety of situations on aerosols (optical thickness at $869 \mathrm{~nm}$ between 0.02 and 0.3 ), glint conditions $\left(L_{\mathrm{g}}\right.$ between 0 and $\left.0.15 \mathrm{sr}^{-1}\right)$, and solar/viewing geometry $\left(\theta_{0}: 15-30^{\circ} ; \theta: 0\right.$ $40^{\circ}$ ). The results, presented in the auxiliary material (Figures S1-S3), suggest that the approach and the GOM-based correction coefficients may be generally applicable in the global ocean. For all cases, the coefficient of determination $\left(\mathrm{r}^{2}\right)$ between MODIS CI and band-ratio Chl is always $>0.9$ for $\mathrm{Chl}<1.0 \mathrm{mg} \mathrm{m}^{-3}$ (slopes and intercepts for the CI-Chl regression, as in Figure 3, range between 0.0078-0.0099 and $0.0125-0.0158$, respectively), with RMS difference between CI-predicted $\mathrm{Chl}$ and band-ratio $\mathrm{Chl}<30 \%$ (Figures S1-S3).

[21] The empirical glint correction is only a partial correction specifically designed to be used with the MODIS CI, where the $T(\theta) T_{0}\left(\theta_{0}\right)$ effect in equation (1) is implicitly removed in equation (3). However, the residual errors from the partial correction, often much weaker in spatial contrast than that of the underlying ocean color patterns, would not affect the interpretations of the various water masses. Indeed, CI images are particularly useful in observing mesoscale ocean circulations because of their significantly improved coverage. For the GOM, the patterns derived from near-daily MODIS data were not only used in qualitative validation of the numerical circulation models (Liu et al., submitted manuscript, 2010), but also used to visually estimate the surface oil trajectory with oil locations determined from MODIS and SAR data and superimposed on the CI images (Figure 2, black outlines). For other subtropical and tropical regions, Figures S1-S3 show the approach's ability to reveal river plume and meso-scale eddy features, including the rings off South Africa associated with the Agulhas Current. Given the extensive sun glint coverage in all subtropical and tropical regions for most time of the year, a similar approach may be implemented for any particular region to derive qualitative ocean color patterns that are otherwise impossible to observe. Such MODIS CI imagery may add important values to any regional ocean observing systems [Weisberg et al., 2009].

[22] One limitation of the approach, however, is that it is specific to the satellite instrument, i.e., all instrument characteristics including calibration are implicitly included in the empirical coefficients. Indeed, when the current coefficients, derived using the MODIS/Aqua instrument, were applied to MODIS/Terra to remove sun glint, significant residual errors occurred. Therefore, the coefficients in equation (3) need to be adjusted for MODIS/Terra, after the significant striping errors are corrected.

\section{Conclusion}

[23] An empirical approach is developed to derive a MODIS color index (CI) using a baseline subtraction method from the Rayleigh-corrected reflectance. MODIS land bands at $500-\mathrm{m}$ and $250-\mathrm{m}$ resolutions are used to avoid saturation, and empirical coefficients are derived from statistics of several GOM images in June 2010 to remove sun glint contamination and to differentiate sun glint from clouds. The objective, as demanded by the various oil-spill response efforts, is to derive color patterns even under the most significant sun glint $\left(L_{\mathrm{g}} \sim 0.15 \mathrm{sr}^{-1}\right)$ to help explain major circulation patterns in the GOM. A preliminary comparison with the "standard" MODIS band-ratio Chl shows that the empirical MODIS CI appears to be a reliable index to represent the surface ocean biomass for most of the GOM ocean waters. Tests in other subtropical and tropical regions suggest that the same approach and empirical coefficients may be applicable in the global ocean.

[24] Acknowledgments. This work is supported by the US NASA Ocean Biology and Biogeochemistry program and Gulf of Mexico program. MODIS data are provided by University of South Florida (F. Muller-Karger) and NASA Goddard Space Flight Center. The help from the NASA SeaDAS team (S. Bailey and B. Franz) in an attempt to remove glint in SeaDAS processing is appreciated. The author is also grateful to two anonymous reviewers for their critical comments and suggestions to test the approach's applicability in the global ocean.

\section{References}

Cox, C., and W. Munk (1954), Measurement of the roughness of the sea surface from photographs of the sun's glitter, J. Opt. Soc. Am., 44, 838-850, doi:10.1364/JOSA.44.000838.

Frey, R. A., S. A. Ackerman, Y. Liu, K. I. Strabala, H. Zhang, J. R. Key, and X. Wang (2008), Cloud detection with MODIS. Part I: Improvements in the MODIS cloud mask for Collection 5, J. Atmos. Oceanic Technol., 25, 1057-1072, doi:10.1175/2008JTECHA1052.1.

Gordon, H. R., and M. Wang (1994), Retrieval of water-leaving radiance and aerosol optical thickness over the oceans with SeaWiFS: A preliminary algorithm, Appl. Opt., 33, 443-452, doi:10.1364/AO.33.000443.

Gower, J., et al. (2005), Detection of intense plankton blooms using the $709 \mathrm{~nm}$ band of the MERIS imaging spectrometer, Int. J. Remote Sens., 26, 2005-2012, doi:10.1080/01431160500075857.

Hochberg, E. J., S. Andrefouet, and M. R. Tyler (2003), Sea surface correction of high spatial resolution Ikonos images to improve bottom mapping in near-shore environments, IEEE Trans. Geosci. Remote Sens., 41 1724-1729, doi:10.1109/TGRS.2003.815408.

$\mathrm{Hu}, \mathrm{C}$. (2009), A novel ocean color index to detect floating algae in the global oceans, Remote Sens. Environ., 113, 2118-2129, doi:10.1016/j. rse.2009.05.012.

$\mathrm{Hu}, \mathrm{C}$. , J. Nelson, E. Johns, Z. Chen, R. Weisberg, and F. E. Muller-Karger (2005), Mississippi River water in the Florida Straits and in the Gulf Stream off Georgia in summer 2004, Geophys. Res. Lett., 32, L14606, doi:10.1029/2005GL022942.

Hu, C., X. Li, W. G. Pichel, and F. E. Muller-Karger (2009), Detection of natural oil slicks in the NW Gulf of Mexico using MODIS imagery, Geophys. Res. Lett., 36, L01604, doi:10.1029/2008GL036119.

Letelier, R. M., and M. R. Abott (1996), An analysis of chlorophyll fluorescence algorithms for the Moderate Resolution Imaging Spectrometer (MODIS), Remote Sens. Environ., 58, 215-223, doi:10.1016/S00344257(96)00073-9.

Liu, A. K., Y. Wu, W. Y. Tseng, and W. G. Pichel (2000), Wavelet analysis of SAR images for coastal monitoring, Can. J. Rem. Sens., 26, 494-500.

McClain, C. R., G. C. Feldman, and S. B. Hooker (2004), An overview of the SeaWiFS project and strategies for producing a climate research quality global ocean bio-optical time series, Deep Sea Res., Part II, 51, 5-42, doi:10.1016/j.dsr2.2003.11.001.

O'Reilly, J. E., et al. (2000), SeaWiFS postlaunch calibration and validation analyses: Part 3, SeaWiFS Postlaunch Tech. Rep. Ser., vol. 11, edited by S. B. Hooker and E. R. Firestone, NASA Tech. Memo., 2000-206892.

Wang, M., and S. W. Bailey (2001), Correction of sun glint contamination on the SeaWiFS ocean and atmosphere products, Appl. Opt., 40, 4790-4798, doi:10.1364/AO.40.004790.

Wang, M., and W. Shi (2006), Cloud masking for ocean color data processing in the coastal regions, IEEE Trans. Geosci. Remote Sens., 44, 3196-3205, doi:10.1109/TGRS.2006.876293.

Weisberg, R. H., et al. (2009), A coordinated coastal ocean observing and modeling system for the West Florida Continental Shelf, Harmful Algae, 8, 585-597, doi:10.1016/j.hal.2008.11.003.

C. Hu, College of Marine Science, University of South Florida, 140 Seventh Ave. S., St. Petersburg, FL 33701, USA. (hu@marine.usf.edu) 